\title{
FORMANDO PROFESSORES INDÍGENAS: O DIREITO À LÍNGUA COMO AÇÃO POLÍTICA*
}

\author{
FORMACIÓN DE MAESTROS INDÍGENAS: EL DERECHO A LA LENGUA COMO ACCIÓN POLÍTICA \\ INDIGENOUS TEACHERS' EDUCATION (DEVELOPMENT): THE RIGHT TO LANGUAGE AS POLITICAL \\ AGENCY
}

\author{
Maria Izabel de Bortoli Hentz ${ }^{* *}$ \\ Universidade Federal de Santa Catarina - UFSC, Florianópolis, BR
}

RESUMO: A formação de professores indígenas representou - e ainda representa - a possibilidade de efetivação do direito à diferença aos povos indígenas e à educação escolar nas línguas maternas de cada povo, reconhecido na Constituição de 1988. Neste trabalho, de caráter bibliográfico e documental, objetiva-se analisar dois processos de formação inicial de professores indígenas, em nível médio, desenvolvidos em Santa Catarina, na relação que estabelecem com projetos de ensino bilíngue no contexto da história da educação escolar indígena. Se, em um momento dessa história as línguas indígenas foram utilizadas como meio de alcançar culturalmente essas populações, para integrá-las ao sistema de ensino nacional, atualmente assumem um papel de empoderamento desses grupos. Nesse sentido, a formação de professores pode se constituir em uma ação que valorize a diversidade linguística. PALAVRAS-CHAVE: formação de professores indígenas; política linguística; ensino de língua.

RESUMEN: La formación de profesores indígenas ha representado - y aún representa - la posibilidad de hacer efectivo el derecho a la diferencia de los pueblos indígenas y a la educación escolar en la lengua materna de cada pueblo, reconocido en la Constitución de 1988. Este trabajo bibliográfico y documental tiene como objetivo analizar dos casos de formación inicial de docentes indígenas en nivel medio, desarrollados en Santa Catarina (Brasil), en la relación que se establece con los proyectos de educación bilingüe en el contexto de la historia de la educación escolar indígena. Si en un momento de la historia se usaron las lenguas indígenas como medio de llegar a estas poblaciones para integrarlas al sistema educativo nacional, actualmente juegan un papel en el empoderamiento de estos grupos. En este sentido, la formación del profesorado puede constituirse en una acción que valora la diversidad lingüística.

PALABRAS-CLAVE: formación de maestros indígenas; política lingüística; enseñanza de idiomas.

ABSTRACT: Indigenous teachers' education represented - and still represents - the possibility of establishment of the right to distinction to indigenous peoples and to education in their mother tongues, recognized in the 1988's Constitution. In this study, developed from a documental and bibliographical perspective, the main goal is to analyze two different processes of indigenous teacher development, in a secondary school level, in Santa Catarina, concerning the relationship that they establish with bilingual teaching projects in the context of the indigenous education. Although in any moment of such history indigenous languages were used as means to culturally reach these peoples in order to integrate them to the Brazilian national education system, nowadays these languages represent empowerment for these groups. In this sense, teachers' education can trigger an action that values linguistic diversity.

KEYWORDS: indigenous teachers' education; language policy; language teaching.

\section{PALAVRAS INICIAIS}

A Declaração Universal dos Direitos Linguísticos, nos artigos 46 e 23, estabelece que "toda comunidade linguística tem direito à preservação de seu patrimônio linguístico e cultural” (OLIVEIRA, 2003, p. 39) e que "a educação deve estar sempre a serviço da diversidade linguística e cultural e das relações harmoniosas entre diferentes comunidades linguísticas do mundo todo" (OLIVEIRA, 2003, p. 33). O Brasil, antes mesmo de sua constituição como nação, já se configurava como país plurilíngue e multicultural. A relação que se estabeleceu e se estabelece entre seus muitos falares reflete e refrata as relações de poder da sociedade brasileira, que também se manifestam nas ações de escolarização da população em diferentes momentos históricos, na medida em que as políticas de educação estão, em alguma medida, ligadas a políticas culturais

\footnotetext{
* Este trabalho foi apresentado como comunicação oral no GT 6: Políticas Linguísticas, durante o Simpósio Internacional Linguagens e Culturas: Homenagem aos 40 anos dos Programas de Pós-graduação em Linguística, Literatura e Inglês da UFSC, realizado entre os dias 04 e O7 de outubro de 2011 . 
mais amplas e são vistas como campo privilegiado para o desenvolvimento e também como centro irradiador dessas políticas.

A história educacional brasileira aponta diferentes momentos em que o objetivo primordial da educação escolar consistia na solução de problemas sociais por meio da escola e não no acesso ao conhecimento das ciências e das artes pelos que a frequentavam. Ilustrativo dessa realidade é o estudo de Santos (1975) acerca dos limites e possibilidades da educação formal para a melhoria das condições de vida dos povos indígenas do sul do Brasil. A tese defendida pelo autor é de que não é possível analisar as ações destinadas à escolarização dos índios, sejam elas efetivadas pelo poder público ou por outras instituições (normalmente, religiosas) sem estabelecer uma relação com as demais ações desenvolvidas pelo Estado e também pelas organizações da sociedade envolvente, quando do atendimento e do estabelecimento de relações com essas populações para que melhorem a sua condição socioeconômica.

O autor destaca a importância de se prestar atenção ao papel da educação escolar para as populações indígenas porque a entende como "uma agência formal do processo destinado a socializar os membros jovens da sociedade que a patrocina” (SANTOS, 1975, p. 12), na medida em que as ações que se desenvolvem na escola não se limitam ao espaço físico da sala de aula.

Assim, se não é possível tomar a escola - não apenas o espaço físico, mas as relações que ali se estabelecem como objeto de estudo, sem considerá-la como organização educativa complexa (NÓVOA, 1992) que uma dada sociedade produz, com objetivos específicos, entende-se que situar a formação de professores indígenas no contexto da história da educação escolar indígena, particularmente nos projetos de ensino bilíngue, pode contribuir para compreendermos melhor as ações de escolarização dessa população empreendidas no passado (marcadamente discriminatórias e repressoras em relação à diversidade linguística) e no presente (que visam à compreensão e valorização dessa diversidade).

Neste trabalho, objetiva-se analisar dois processos de formação inicial de professores indígenas, em nível médio, desenvolvidos em Santa Catarina, na relação que estabelecem com projetos de ensino bilíngue no contexto da história da educação escolar indígena. Para este estudo, os dados de análise são constituídos pelos os projetos pedagógicos do Curso de formação e habilitação de professores de $1^{\mathrm{a}}$ a $4^{\mathrm{a}}$ séries do Ensino Fundamental para o contexto indígena Xokleng e Kaingang e do Curso de Formação de Professores Guarani do Sul e Sudeste do país - Kuo'a - Mbo'e - Conhecer - Ensinar, mais especificamente a matriz curricular de cada um desses cursos, e os Pareceres no 248/1998/CEE-SC e n 295/2002/CEE-SC, que aprovam ambos os projetos pedagógicos. $\mathrm{Na}$ medida do necessário, recorreu-se a relatórios e registros relativos à implantação desses cursos, que constam dos arquivos do Núcleo de Educação Indígena - NEI, bem como a documentos das escolas às quais se vinculavam os professores que realizaram os cursos.

Trata-se, portanto, de um estudo de caráter documental e, ao realizá-lo, pretende-se contribuir para a reflexão acerca de como um processo dessa natureza pode se constituir em uma ação política que valorize (ou não) a diversidade linguística. Dizendo de outro modo: a concepção que fundamenta o projeto pedagógico de um curso pode contribuir de forma mais (ou menos) significativa e efetiva para que a garantia do direito ao ensino nas línguas maternas de cada povo indígena assuma de fato um papel de empoderamento desses grupos e não de discriminação e exclusão, como já o foi.

Para uma melhor compreensão do fenômeno em análise, na primeira seção, retoma-se a constituição histórica da educação escolar indígena, voltando-se o olhar para os processos de formação de professores que se desenvolveram em diferentes momentos, tendo em vista a constituição de políticas de ensino bilíngue. Ainda nessa seção, reflete-se sobre a concepção de bilinguismo que fundamentou essas políticas e o processo de formação nelas implicadas. Na segunda seção, os dois cursos de formação de professores indígenas que se desenvolvem em Santa Catarina no contexto da $4^{\mathrm{a}}$ fase da história da educação escolar indígenas, assim como a relação que esses processos podem ter com a construção de projetos pedagógicos para as escolas indígenas de educação básica, são colocados em tela e analisados.

\section{A CONSTITUIÇÃO HISTÓRICA DA EDUCAÇÃO ESCOLAR INDÍGENA}

O processo educacional brasileiro iniciou ainda no Brasil Colônia, mais especificamente com a chegada dos padres jesuítas. Estes tinham como atribuição evangelizar os índios, manter a fé católica na colônia e professar a cultura portuguesa. 
É nesse contexto que se insere a primeira fase da história da educação escolar para os povos indígenas. Ferreira (2001) a define como a fase da catequese, uma vez que considera que a educação escolar, entre outras coisas, foi usada como meio para promover a assimilação dos índios à civilização cristã e para incorporá-los à sociedade nacional como mão-de-obra. Segundo a autora, este é o primeiro e mais longo momento da história da educação escolar para os índios no Brasil. Destacam-se nesse período as missões, os internatos e aldeamentos.

O segundo período da história da educação escolar para os índios no Brasil, definido como a fase da integração dos índios à comunhão nacional, fundamenta-se na compreensão da escolarização dos índios como um instrumento que podia "assegurar, antes de tudo, os objetivos da sociedade dominante" de promover um projeto capitalista de desenvolvimento para o país, no qual o índio, em seu estado original, não tinha mais espaço. Tornava-se necessário, portanto, integrá-lo à cultura dominante (SANTOS, 1975, p. $54)$.

O marco da segunda fase, segundo Ferreira (2001), foi a criação do Serviço de Proteção aos Índios - SPI, em 1910, que teria por função colocar em prática uma política indigenista menos desumana, baseada nos ideais positivistas do início do século. No que se refere à educação escolar, a preocupação com a diversidade linguística e cultural foi colocada em pauta, mas o pequeno número de índios em cada povo não justificou ações voltadas ao ensino bilíngue e, consequentemente, à formação de professores. Na prática, o que ocorreu na escola nesse período foi um menor tempo dedicado ao ensino religioso e uma ênfase maior ao trabalho agrícola e doméstico, já que o objetivo era a integração do índio à sociedade nacional.

Com a extinção do SPI e a criação da Fundação Nacional do Índio - FUNAI, em 1967, o ensino bilíngue ${ }^{1}$ passou a fazer parte da política de educação proposta a partir de então. Uma das ações para a viabilização dessa proposta foi a capacitação de índios para que pudessem assumir funções educativas em suas comunidades. No projeto desenvolvido pelo SIL, as ações de formação assumiram um papel fundamental.

Uma experiência de ensino bilíngue representativa dessa segunda fase da história da educação escolar indígena foi analisada por Santos (1975) no estudo que desenvolveu acerca das ações de atendimento escolar que foram implementadas nos postos indígenas da região sul ${ }^{2}$ do Brasil. Para o autor, o princípio que caracterizou esse projeto de ensino bilíngue, bem como a estrutura geral do seu funcionamento nas escolas, foi a atuação dos índios como monitores para atenderem as crianças que não sabiam o português quando chegavam à escola pela primeira vez. Para tanto, foram organizadas e desenvolvidas ações específicas de formação de modo a garantir o êxito no desenvolvimento do projeto.

Assim, em lugar da criançada ser iniciada nas atividades de alfabetização em língua portuguesa, ela seria colocada sob os cuidados do professor-índio, durante 4 semestres letivos, objetivando primeiro a sua alfabetização na língua indígena, seguido em simultâneo com o aprendizado oral do português e depois a sua alfabetização nessa língua. (SANTOS, 1975, p. 65).

Para Santos (1975), o maior problema das ações educacionais - aqui incluída a experiência de ensino bilíngue - que se desenvolviam nas aldeias da região sul estava na distância existente entre os meios pelos quais as sociedades indígenas formavam e educavam suas novas gerações e a maneira pela qual eram formadas e educadas as crianças e jovens da sociedade ocidental. Entre os índios, o processo centrava-se nos sistemas de socialização da cultura tradicional e estes não eram formalizados, ocorriam nas relações cotidianas que se estabeleciam entre os que já haviam se apropriado dos conceitos e valores a serem

\footnotetext{
1 Como não havia programas educacionais bilíngues para as muitas línguas indígenas faladas no Brasil, a FUNAI recorreu ao Summer Institute of Linguistics - SIL. Considerando que o objetivo da FUNAI era instaurar uma política indigenista internacionalmente aceita e cientificamente fundamentada, o caráter acadêmico do SIL pode ter sido decisivo para os convênios que foram firmados. Dentre as razões apontadas para a adoção do modelo do SIL, Ferreira chama atenção para aquela que se refere à garantia da "integração eficiente dos índios à sociedade nacional, uma vez que os valores da sociedade ocidental seriam traduzidos nas línguas nativas e expressos de modo a se adequar às concepções indígenas" (FERREIRA, 2001, p. 77).

2 Segundo Santos (1975), as bases dessa proposta foram formuladas pela missionária Ursula Wiesemann, linguista de longa experiência e com domínio seguro dos diversos dialetos Kaingang. O projeto foi apresentado à representação regional da FUNAI que, em fevereiro de 1970, instalou o primeiro curso para a preparação dos professores, no Centro de Treinamento Clara Camarão, em Guarita-RS, uma vez que um dos pressupostos básicos era o envolvimento dos índios como monitores bilíngues, depois de um período de preparação. O curso, além de preparar os monitores, tinha os objetivos de garantir o seu entrosamento com os professores não índios e de promover a reciclagem dos últimos e dos responsáveis pelo programa, no setor de educação dos postos da FUNAI. O autor destaca, ainda, que o funcionamento do centro e o curso de formação foram possíveis pela cooperação estabelecida entre a FUNAI e o SIL, este último responsável pela elaboração de cartilhas, livros, cartazes e outros materiais didáticos utilizados tanto na formação como no desenvolvimento das aulas com as crianças indígenas.
} 
socializados e aqueles que ainda não tinham aprendido. "Na sociedade indígena o saber é aprendido no fazer prático e não fora dessa realidade” (SILVA, 2001, p. 233).

$\mathrm{Na}$ sociedade ocidental, o processo educacional das gerações mais jovens está centrado nos sistemas formalizados de ensino. Como a escola que se ofereceu aos índios foi pensada nessa mesma ótica, acabou se constituindo em instrumento de inculcação ideológica.

Nessa segunda fase da história da educação escolar para os índios, tanto Santos (1975), quando analisa as atividades educacionais, quanto Ferreira (2001), quando caracteriza o movimento de integração dos índios à comunhão nacional, explicitam a contradição da retórica da FUNAI de que o ensino bilíngue seria o meio para assegurar às comunidades indígenas sua diversidade linguística e cultural. Nas palavras de Silva (2001, p. 39), "as línguas indígenas tornaram-se instrumentos de sua própria extinção. Eram usadas apenas na introdução do sistema do ensino nacional, realizado nas aldeias indígenas, de forma acrítica e alienante”.

Os autores demonstram em suas análises que, contrariamente ao que se afirmava, o ensino bilíngue se constituiu, na prática, em meio para garantir a integração dos índios à sociedade nacional. Isso significa dizer que se fazia uso da língua indígena para traduzir os valores da sociedade nacional que, aos poucos, iam substituindo as concepções tradicionais dos povos indígenas.

A partir do final dos anos 60 e no decorrer da década de 70 do Século XX, grupos organizados da sociedade civil e de comunidades indígenas começaram a viabilizar um novo período na história da educação para essas populações que têm reconhecido, no texto constitucional, o direito à diferença. Isso representou uma atitude de rompimento com a postura integracionista, que entendia as populações indígenas como categoria étnica e social transitória, fadada ao desaparecimento. Ferreira entende que

A atuação das organizações não-governamentais pró-índio [com a participação expressiva das universidades e setores progressistas da Igreja Católica] e a respectiva articulação com o movimento indígena [que organiza as lideranças em nível nacional por meio da realização de assembleias, desde 1974] fizeram com que se delineasse uma política e uma prática indigenista paralela a oficial, visando à defesa dos territórios indígenas, à assistência à saúde e à educação escolar. (FERREIRA, 2001, p. 87).

Esse quadro viabilizou a organização de projetos alternativos para a escolarização dos índios que, aos poucos, se concretizaram em experiências de autoria de professores indígenas - terceira e quarta fases da história da educação escolar indígena, respectivamente. Dentre os muitos que iniciaram nesse período e que ainda continuam a se desenvolver, destaca-se o projeto de educação indígena denominado "Uma experiência de autoria”, de responsabilidade da Comissão Pró-Índio do Acre - CPI/ACs.

O princípio da autoria constitui a base dos pressupostos e objetivos políticos e pedagógicos do projeto que a $\mathrm{CPI} / \mathrm{AC}$ desenvolve e, em alguma medida, de outros que caracterizam a terceira e a quarta fase da história da educação escolar indígena ${ }^{4}$. Os objetivos, os conteúdos, as atividades, os materiais didáticos e a forma de avaliação, tanto de cursos de formação dos quais os professores participam como do que é ensinado nas escolas pelos professores, são elaborados ao longo do processo de formação pelos próprios professores, ainda que muitas vezes tenham de ser assessorados. A escola indígena passa, então, a ser entendida como

uma escola organizada e controlada no cotidiano pelos professores e comunidade indígena, orientada para atender as suas necessidades e expectativas; uma escola, portanto, onde os próprios professores e seus alunos sejam os autores principais do conjunto de aspectos que constituem o 'currículo de fato' experimentado por eles nas aldeias. (MONTE, 1996, p. 12).

Com base nesse princípio, os cursos de formação de professores indígenas se constituíram/constituem, de um lado, em locus para escolarização e formação profissional dos já (outros, futuros) professores indígenas e,

\footnotetext{
3 A CPI/AC é uma entidade não-governamental que desenvolve ações de assessoria às lutas indígenas no campo da educação, saúde, luta pela demarcação das Terras Indígenas e sua ocupação produtiva e ambientalmente correta. A proposta de educação para as escolas indígenas se desenvolve desde 1983, em decorrência de uma demanda formulada inicialmente por lideranças indígenas Kaxinawá. Consiste fundamentalmente na formação de jovens e adultos das próprias comunidades indígenas para a docência. Nesse processo, são capacitados para a formulação e prática de currículos interculturais e bilíngues e para a produção de materiais didático-pedagógicos. Para um maior aprofundamento acerca dessa experiência, ver Monte (1996; 2003a; 2003b).

4. O projeto Tucum (PEGGION, 2003), a formação de educadores indígenas para as escolas xinguanas (TRONCARELLI et al, 2003), o programa de formação de professores indígenas Krenak, Maxacali, Pataxó e Xakriabá em Minas Gerais (DUTRA et al, 2003), o projeto de educação diferenciada entre os índios do Uaçá (TASSINARI, 2001) são alguns exemplos representativos do que se realiza no tocante à educação escolar indígena na fase conhecida como a da formação de projetos alternativos e de experiências de autoria.
} 
de outro, em locus para gestar e para construir uma escola diferente da que já conheciam para as populações indígenas pela produção do material didático, um dos meios pelos quais se efetiva o ensino e a aprendizagem das crianças e jovens nas escolas das aldeias.

A educação intercultural constitui, para Monte (2003a, 2003b) a dimensão identitária desse processo de formação, e, por que não dizer, da escola indígena, diferentemente do que ocorreu no processo de formação de monitores bilíngues da segunda fase da história da educação escolar indígena, cuja experiência foi analisada por Santos (1975) e apresentada como exemplo ilustrativo daquele período neste trabalho.

A sistematização das discussões em encontros, reuniões, cursos, assembleias e congressos acerca da educação para os povos indígenas e das experiências educacionais interculturais e bilíngues em terras indígenas foi se constituindo em contribuição efetiva para os textos de caráter legal e normativo (leis, decretos, portarias, resoluções $)^{5}$ e também para outros documentos oficiais ${ }^{6}$, de caráter referencial, que sustentam a política de ação do poder público no atendimento ao direito de uma educação diferenciada para as comunidades indígenas.

Formaliza-se e oficializa-se, assim, uma discussão que já se convertia em ações concretas em muitas escolas indígenas do país. A par das críticas que se pode fazer à apropriação e institucionalização, pelo poder público, de conceitos gestados a partir de práticas efetivas não mais sob os princípios da integração, pode-se considerar, também, que o processo desencadeado para a elaboração e discussão do RCNEI (para citar um exemplo desse movimento) possibilitou que a comunidade indígena, e também os responsáveis pelas políticas públicas de ação a ela afetas, que ainda não haviam conseguido alcançar tal nível de reflexão se envolvessem no debate acerca das práticas de escolarização a que a escola indígena estava submetida7.

\subsection{Nas políticas de ensino bilíngue, diferentes compreensões de bilinguismo}

Ao se retomar a constituição histórica da educação escolar para as populações indígenas e, nesta, as políticas de ensino bilíngue, é importante considerar a compreensão de bilinguismo que as fundamentam. Maher (2007), em uma de suas muitas reflexões acerca da educação bilíngue e intercultural para falantes cuja língua materna não é o português, destaca que esta pode ser vista positivamente, quando as línguas envolvidas são as de prestígio; porém, se as línguas a serem ensinadas não forem as de prestígio, como as indígenas, esse ensino quase sempre é visto como um problema. Para a autora, na avaliação social do aluno bilíngue, além do status das línguas envolvidas, entram em cena os valores sociais das variedades dialetais e linguísticas que este aluno domina. Assim, não basta aprender e dominar mais de uma língua, mas sim as variedades socialmente valorizadas dessas línguas.

No caso da experiência ilustrativa da segunda fase da história da educação para as populações indígenas, pode-se concluir que o bilinguismo foi encarado como um problema e que as ações de escolarização fundamentaram-se no "Modelo Assimilacionista de Transição" (MAHER, 2007, p. 70). Em tal modelo,

a língua de instrução, nas séries iniciais, é a língua materna do aluno. Assim que a criança é nela alfabetizada, assim que ela entende o funcionamento da escrita, vai-se paulatinamente, introduzindo o português até que a língua materna seja totalmente excluída do currículo escolar (MAHER, 2007, p. 70).

Para a autora, o ensino bilíngue fundamentado nesse modelo tem como objetivo a retirada da língua materna do repertório do falante. Para tanto, "o aluno começa sua escolaridade monolíngue na língua minoritária, passa para um bilinguismo transitório e termina monolíngue na segunda língua, na língua portuguesa" (MAHER, 2007, p. 70).

Pode-se entender, no entanto, que uma avaliação positiva do bilinguismo (MAHER, 2007) fundamenta os projetos de educação escolar indígena que se desenvolvem no contex to da terceira e quarta fases da história

\footnotetext{
5 A Constituição Federal de 1988, o Decreto Presidencial no 26/91; a Portaria Interministerial nº 559/91; a Lei de Diretrizes e Bases da Educação Nacional - LDB (Lei 9394/96); o Parecer CNE/CEB n 14/1999; a Resolução nº 03/1999 são exemplos de textos de caráter legal e normativo que instituem no Estado brasileiro o conceito jurídico de terras indígenas e de educação intercultural e bilíngue, entre outros.

6 As Diretrizes para a Política Nacional de Educação Escolar indígena, publicadas pelo MEC em 1993, e o Referencial Curricular Nacional para as Escolas Indígenas - RCNEI, também lançado pelo MEC em 1998, são exemplos de documentos oficiais que incorporam o princípio da autoria.

7 É o que ocorre em Santa Catarina, quando educadores índios e não-índios, representantes de organizações não-governamentais ligadas à causa indígena, antropólogos, linguistas e comunidades indígenas elaboram o texto Educação Escolar Indígena, no contexto do processo de revisão e aprofundamento da Proposta Curricular do Estado.
} 
de escolarização dessas populações, na medida em que a situação linguística dos diferentes povos indígenas não é considerada um problema para os que nela e com ela se envolvem. O objetivo da proposta de educação bilíngüe desencadeada pela CPI/AC em 1983, e de tantas outras que dela se aproximam, é a manutenção e o desenvolvimento das línguas indígenas na e pela escola. Um projeto de ensino bilíngue dessa natureza fundamenta-se no "Modelo de Enriquecimento Linguístico" (MAHER, 2007, p. 71).

Nesse modelo de ensino bilíngue, a língua minoritária (nesse caso, as línguas indígenas) se constitui "na língua de instrução ao longo de todo o processo de escolarização" e a língua majoritária (nesse caso, o português) "deve ser adicionada ao repertório comunicativo do aluno, sem, contudo, deixar de se investir no aumento de competência de uso em sua língua materna" (MAHER, 2007, p. 71-72). Segundo a autora, com base no Modelo de Enriquecimento Linguístico, promove-se um bilinguismo aditivo, diferentemente do bilinguismo subtrativo, resultado do Modelo Assimilacionaista de Transição, que fundamentou as políticas de ensino bilíngue da primeira e da segunda fases da história da educação escolar indígena no Brasil.

Considerando os preceitos constitucionais e as diretrizes do MEC, que apontam para a elaboração de um currículo intercultural e bilíngue, específico e diferenciado, que contemple o Sistema Educacional da sociedade envolvente e, ao mesmo tempo, preserve as culturas e tradições das comunidades indígenas, ainda são necessárias ações e programas específicos que visem à formação de recursos humanos para o exercício da docência entre os próprios indígenas, considerando suas tradições socioculturais e estimulando a emergência de metodologias de ensino que garantam a produção de uma literatura e de uma pedagogia específicas às línguas nativas. Na seção seguinte, serão apresentadas e discutidas duas experiências de formação de professores indígenas em Santa Catarina, engendradas no contexto da quarta fase da história da educação escolar indígena proposta por Ferreira (2001).

\section{A FORMAÇÃO DE PROFESSORES INDÍGENAS EM SANTA CATARINA: REFLEXÕES SOBRE A EXPERIÊNCIA RECENTE}

Se para alguns povos indígenas a história da educação escolar tem início e se desenvolve ainda no Brasil Colônia, na fase denominada de catequese, para os povos que vivem em Santa Catarina, a sua gênese ocorre muito depois desse período. Isso não significa, porém, que os Guarani, Kaingang e Xokleng tenham passado imunes às ações da escola integracionista. É no contexto da segunda fase da história da educação para os povos indígenas que se inicia a escolarização sistemática dos índios que aqui viviam. Porém, há indicativos de que, por volta de 1925, Mieczyslaw Brzezinsk, um professor polonês, tenha organizado uma escola e desenvolvido ações exitosas de alfabetização entre os índios Xokleng (SANTOS,1998).

Em trabalhos anteriores, Hentz (2005, 2007) observou-se que o atendimento escolar nas terras indígenas 8 é resultado da luta empreendida em cada uma das aldeias que se organiza, mesmo antes de terem esse direito garantido na Constituição de 1988. Pelo estudo realizado, a primeira escola para os Xokleng foi criada no ano de 1940 e foi a única até 1973 . À época do estudo, das oito escolas que se situavam nas diferentes aldeias da Terra Indígena Laklanõ, cinco foram criadas depois de 1990. Inicialmente, por leis municipais, integrando o sistema de ensino do município em que se localizavam geograficamente e, em 1999, por força do Decreto Estadual n ${ }^{\circ}$ 058, de 26 de fevereiro, passaram a integrar o sistema estadual de ensino.

Estabelecendo um paralelo entre o movimento vivenciado pelas comunidades indígenas de Santa Catarina na luta pela viabilização do direito à escola indígena específica e diferenciada, intercultural e bilíngue e comunitária, com o movimento dos agentes públicos responsáveis pelas ações nessa direção, constata-se que somente a partir de 1994 é que se intensifica o debate acerca da educação escolar indígena no âmbito da Secretaria de Estado da Educação, com a estruturação do Núcleo de Educação Indígena - NEI (instituído oficialmente em 1996 (Portaria E 414/1996), portanto seis anos depois do que previa a Portaria Interministerial 559/91). Isso significa que, enquanto em alguns estados já se desenvolviam programas de formação para professores indígenas, quer pela atuação de ONGs quer pela ação do poder público, o setor governamental responsável por essa tarefa nesse Estado tinha muito a fazer.

\footnotetext{
8 Ainda que o estudo aqui referido remeta mais especificamente à história do atendimento escolar para o povo Xokleng, pelo estudo de Santos (1975), entre outros, entende-se que o movimento vivenciado na construção da escola indígena por esse povo é ilustrativo do movimento vivenciado pelos demais povos em Santa Catarina.
} 
É no contexto das ações que se desenvolveram a partir deste momento que se situam os dois processos de formação de professores indígenas9, cujos projetos pedagógicos serão analisados na sequência: 1) o Curso de formação e habilitação de professores de $1^{\mathrm{a}}$ a $4^{\mathrm{a}}$ séries do Ensino Fundamental para o contexto indígena Xokleng e Kaingang e 2) o Curso de Formação de Professores Guarani do Sul e Sudeste do país - Kuo’a Mbo'e - Conhecer - Ensinar. Ambos os cursos foram aprovados pelo Conselho Estadual de Educação CEE/SC 10, como experiências pedagógicas, em turmas únicas, ofertadas em regime especial (em etapas presenciais - concentradas e intercaladas ao longo do ano letivo, preferencialmente nos períodos de férias escolares - e à distância - 20\% da carga horária total de cada um dos cursos), já que muitos dos alunos eram professores e atuavam em sala de aula, nas escolas de suas aldeias.

A extinção da categoria de professor leigo, ou seja, daquele profissional que atuava na área da educação sem formação específica (prevista na Lei 9224/96 - FUNDEF) foi uma das razões que justificou a proposição dos dois cursos de formação, uma vez que este era o caso dos professores indígenas que atuavam nas escolas de suas comunidades na época. A justificativa pedagógica dos projetos pedagógicos desses dois cursos fundamentava-se na compreensão de Nóvoa (1995) para a formação de professores. Para o autor, uma ação dessa natureza precisa considerar esse profissional como pessoa, como decisor/interventor e como produtor de conhecimento. Pode-se concluir que essa perspectiva sintetiza-se nos objetivos de ambos os cursos, expressos nos respectivos projetos pedagógicos:

Capacitar o aluno [muitos deles, já professores] a construir coletivamente uma proposta curricular das séries iniciais específica e diferenciada, intercultural e bilíngue, ou seja, uma proposta com organização curricular, conteúdos, metodologia, calendário escolar, avaliação e material didático que expressem a cosmovisão e o modo de ser Kaingang e Xokleng. (PARECER Nº 248/98 - CEE/SC, p. 6);

Formar professores Guarani para que se tornem pesquisadores de sua própria cultura, alfabetizadores em sua língua materna e mediadores de um ensino bilíngue e intercultural”; [...]

Habilitar professores Guarani para serem autores de seus próprios materiais didáticos em sua língua materna e em português, considerando sua cultura. (PARECER Nº 295/2002 - CEE/SC, p. 2).

Ainda que muito semelhantes nos princípios legais e pedagógicos que fundamentaram os projetos pedagógicos desses dois cursos, há algumas especificidades que os distinguem, conforme será exposto nas seções seguintes.

\subsection{O curso de formação de professores para o contexto Xokleng e Kaingang}

O Curso de formação e habilitação de professores de $1^{\mathrm{a}}$ a $4^{\mathrm{a}}$ séries do Ensino Fundamental para o contexto indígena Xokleng e Kaingang foi proposto para atender 50 índios Xokleng e Kaingang de Santa Catarina (preferencialmente os que atuavam como professores leigos) ${ }^{11}$, organizados em duas turmas, uma para cada etnia, com matriz curricular específica, perfazendo um total de $2.590 \mathrm{~h} / \mathrm{a}$ em cada uma delas. Cabe ressaltar que se trata de um único curso, com apenas um projeto pedagógico, mas que se efetivaria em duas turmas, com matrizes curriculares específicas a cada uma delas. Na análise de ambas, constata-se que nas disciplinas da base comum nacional ${ }^{12}$ as duas grades curriculares se equivalem; das cinco disciplinas que compõem a parte específica, duas delas distinguem uma grade da outra (História e Organização Social Kaingang e Língua Kaingang / História e Organização Social Xokleng e Língua Xokleng) ${ }^{13}$; nas disciplinas

\footnotetext{
9 Atualmente está em desenvolvimento na Universidade Federal de Santa Catarina o Curso de Licenciatura Intercultural Indígena do Sul da Mata Atlântica. Este curso, no entanto, não constitui objeto de análise deste trabalho.

10 Parecer nº 248/1998/CEE-SC e Parecer nº 295/2002/CEE-SC, respectivamente.

11 As atividades desse curso iniciaram em julho de 1999 e foram concluídas em novembro de 2002, com a formatura de 47 professores índios Kaingang e Xokleng.

12 Língua Portuguesa e Literatura, História, Geografia, Matemática, Química, Física, Biologia, Esportes e Arte eram as disciplinas da base comum nacional desse curso.

13 Sociologia Cultural, Metodologia da Pesquisa e Saúde Pública eram as disciplinas da parte específica da matriz curricular comuns às turmas Kaingang e Xokleng.
} 
profissionalizantes, apenas uma estabelece diferença entre uma e outra grade (Metodologia do Ensino da Língua Kaingang / Metodologia do Ensino da Língua Xokleng), sendo as demais comuns às duas grades ${ }^{14}$.

Estabelecendo a relação da grade curricular desse curso com a de outros cursos de formação e habilitação de professores de mesmo nível (conhecidos como Cursos de Magistério) não se observam diferenças significativas entre uma e outra, o que pode justificar a observação que consta abaixo da proposta de cada uma das grades curriculares, às f. 03 e 04 do Parecer $n^{\circ}$ 248/98 - CEE/SC: "todas as disciplinas serão trabalhadas considerando a especificidade e diferença bem como a interculturalidade". Sobre essa mesma questão, no item que se refere ao desenvolvimento do projeto, às f. 05 do mesmo parecer, afirma-se que "todas as disciplinas de base comum, dentro do possível, procurarão se adequar à ótica das culturas Kaingang e Xokleng, estabelecendo relações com o já conhecido e fornecendo instrumental para que o professor-aluno, indague-se e busque conhecer mais sobre sua própria realidade”. Sobre as disciplinas de base específica, observa-se que deverão ser "trabalhadas em duas turmas distintas agrupadas conforme sua etnia".

A semelhança da matriz curricular desse curso com a de Cursos de Magistério e as observações que constam do Parecer $n^{\circ}$ 248/98 - CEE/SC que o aprova sugerem que, apesar de proposta para atender a necessidades e demandas específicas, não incorpora de fato os princípios das discussões e orientações para a formação de professores indígenas produzidas até então, muito provavelmente resultado do não envolvimento no movimento de discussão acerca da educação escolar indígena, que se desenvolveu de forma efetiva em muitas regiões do Brasil, desde meados dos anos 1970. A proposição de duas grades curriculares, uma para o grupo de alunos Xokleng e outra para os Kaingang, também pode ser indicativo disso, uma vez que um dos princípios da educação escolar indígena é a interculturalidade e não se observa nenhuma ação na direção de cada um desses grupos conhecer, ainda que minimamente, de forma sistemática, aspectos específicos da língua, da cultura, da arte, da história e da organização social do outro ou ainda de outros povos indígenas.

\subsection{O curso de formação de professores para o contexto Guarani}

O Curso de Formação de Professores Guarani do Sul e Sudeste do país - Kuo’a - Mbo'e - Conhecer Ensinar - foi proposto para atender a 60 índios Guarani dos Estados de Santa Catarina, Paraná, Rio Grande do Sul, São Paulo e Rio de Janeiro ${ }^{15}$, que atuavam como professores ou interessados em assumir a docência, de acordo com a necessidade de cada comunidade. A grade curricular deste curso incluiu disciplinas da Base Comum ${ }^{16}$, cujo objetivo era "trabalhar o conhecimento dessas diferentes ciências de forma articulada com a metodologia, a pesquisa e a didática de ensino desses mesmos conhecimentos para as séries iniciais". As questões específicas da cultura guarani foram abordadas "a partir de eixos temáticos que permitiram trabalhar com os conhecimentos matemáticos, cosmológicos, da relação com a terra e com a natureza, dentre outros e constituíram a parte diversificada" (PCEE 170/020, 2002, p. 13). A organização da pesquisa acerca desses conhecimentos e da sistematização dos resultados ficaram sob a responsabilidade da disciplina Metodologia e Desenvolvimento de Pesquisa Multicultural. As disciplinas de Fundamentos e Legislação da Educação constituíram a base profissionalizante desse curso, na qual foram privilegiados conhecimentos relativos à formação de professores.

A carga horária total desse curso compreendeu 4.000 horas. Destas, 2.400 foram efetivadas na modalidade presencial em etapas intensivas centralizadas e etapas intensivas descentralizadas. As etapas presenciais centralizadas (1.920 horas) foram dedicadas às atividades de ensino e aprendizagem dos conhecimentos da cultura ocidental, possibilitando aos futuros professores o diálogo desses conhecimentos com os da cultura Guarani. As etapas presenciais descentralizadas (480 horas) foram realizadas nas comunidades dos alunos e

\footnotetext{
14 Fundamentos da Educação, Estrutura e Funcionamento do Ensino Fundamental, Didática, Metodologia da Alfabetização e da Leitura, Metodologia do Ensino de Arte, Metodologia do Ensino de Matemática, Metodologia do Ensino de Estudos Sociais, Metodologia do Ensino Bilíngue e Metodologia do Ensino de Esportes e o Estágio Supervisionado eram as disciplinas profissionalizantes comuns às duas grades curriculares do Curso de formação e habilitação de professores de $1^{\mathrm{a}}$ a $4^{\mathrm{a}}$ séries do Ensino Fundamental para o contexto indígena Xokleng e Kaingang.

$15 \mathrm{O}$ envolvimento de diferentes Estados na organização e oferta desse curso foi possível devido a um protocolo de intenções firmado entre as instituições parceiras: Ministério da Educação - MEC, Fundação Nacional do Índio - FUNAI e as Secretarias de Estado da Educação dos Estados de Santa Catarina, Paraná, Rio Grande do Sul, Espírito Santo, Rio de Janeiro e São Paulo.

16 Língua Guarani, Língua Portuguesa e Literatura, Artes, Geografia, História e Organização Social Guarani, Antropologia, Sociologia, Ciências (Física Química, Biologia e Saúde Pública) e Matemática constituem as disciplinas da Base Comum no projeto pedagógico deste curso.
} 
contaram com a participação e colaboração dos especialistas/pensadores/sábios Guarani: artesãos, narradores de mitos, compositores, músicos, entre outros. Do total da carga horária do curso, 1.200 horas se efetivaram em atividades individuais e coletivas de estudos orientados, pesquisa nas comunidades, tendo em vista e elaboração do projeto político pedagógico da escola Guarani. Essas atividades estiveram vinculadas à disciplina Metodologia e Desenvolvimento de Pesquisa Multicultural e se desenvolveram ao longo do período do curso (2003-2009). O estágio supervisionado compreendeu 400 horas e se efetivou através de atividades de observação, participação e regência de classe em turmas de anos iniciais do ensino fundamental de escolas Guarani.

Como se pode perceber, o Curso de Formação de Professores Guarani do Sul e Sudeste do país - Kuo’a Mbo'e - Conhecer - Ensinar - se distingue do Curso de formação e habilitação de professores de $1^{\mathrm{a}}$ a $4^{\mathrm{a}}$ séries do Ensino Fundamental para o contexto indígena Xokleng e Kaingang no que se refere à constituição do grupo de alunos e ao projeto pedagógico que se materializa na composição da matriz curricular (disciplinas), na carga horária total do curso e na descrição de sua forma de efetivação. Com relação à composição do grupo, destaca-se o fato de os alunos serem de diferentes estados do Brasil, ainda que da mesma etnia, o que possibilitou o diálogo entre as especificidades vivenciadas nas diferentes comunidades para a resolução de situações-problema muitas vezes semelhantes.

A diferença mais significativa consiste na matriz curricular e esta interessa particularmente à discussão que aqui se desenvolve. Inicialmente não se fez a distinção entre as disciplinas das áreas de conhecimento específico (que constituem a base comum nacional) e as suas metodologias. Por exemplo: na disciplina de Língua Portuguesa, ao mesmo tempo em que se propôs o trabalho com os conhecimentos específicos dessa disciplina, propôs-se o trabalho com a metodologia de ensino dessa disciplina nas séries iniciais do ensino fundamental. Outro destaque refere-se a um equilíbrio na distribuição da carga horária entre as disciplinas: 1.920 horas para o estudo dos conhecimentos da cultura ocidental e 1.680 horas para o aprofundamento e a sistematização dos conhecimentos da Cultura Guarani. Nas 400 de estágio, que pelo projeto pedagógico do curso deveriam ser realizadas em escolas Guarani, previa-se a efetivação desse equilíbrio quando da proposição da utilização da língua Guarani como língua de instrução.

\subsection{O projeto de formação de professores Guarani e o projeto pedagógico de uma escola Guarani: uma possível relação}

No projeto pedagógico do Curso de Formação de Professores Guarani do Sul e Sudeste do país - Kuo’a Mbo'e - Conhecer - Ensinar -, mais especificamente na composição da carga horária estava previsto que, do total da carga horária do curso, 1.200 horas seriam efetivadas em atividades individuais e coletivas de estudos orientados, pesquisa nas comunidades, tendo em vista e elaboração do projeto político pedagógico da escola Guarani.

A análise do projeto político pedagógico de uma escola Guarani da grande Florianópolis, cujos professores participaram desse curso, pode contribuir para compreender como pequenas diferenças na concepção de um projeto de formação de professores podem provocar mudanças significativas no processo de ensino e de aprendizagem na escola de educação básica. Na sequência, algumas breves referências à organização curricular e à concepção de metodologia deste projeto de escola que, entende-se, reflete e refrata aspectos da concepção de formação vivenciada por parte significativa de seus professores.

O primeiro aspecto que chama atenção no projeto político pedagógico desta escola é a organização do currículo do Ensino Fundamental em quatro grandes eixos temáticos e não por disciplinas: 1) Cerimônias (cura ou medicina, consagração das relações, conteúdos complementares), 2) Ciclo de vida (da mulher e do homem, rituais e crenças, conteúdos complementares) 3) Cultura (alimentação tradicional, origem dos alimentos, mata, sistema de plantio Guarani, plantas introduzidas, conteúdos complementares) e 4) Tekoa (comunidade, escola, hierarquia, normas internas, relações interculturais, conteúdos complementares). Os conhecimentos relativos a cada um desses temas são trabalhados em todas as turmas (organizadas de forma multisseriada), com ênfases diferenciadas. No sub-tema "conteúdos complementares", estão indicados os conhecimentos das diferentes ciências que integram o currículo das escolas de um modo geral (que se relacionam ao grande eixo em estudo) a serem privilegiados em cada série.

Como segundo aspecto, destaca-se a concepção de metodologia para o ensino e a aprendizagem dos diferentes conhecimentos que constituem o currículo dessa escola. Em linhas gerais, o processo parte do 
conhecimento prévio do aluno acerca de cada um dos temas e sub-temas e se desenvolve com a efetiva participação dos alunos nos eventos e atividades que são objeto de estudo na escola, o que requer e valoriza a participação ativa dos mais velhos na aprendizagem das gerações mais jovens. Também são desenvolvidas atividades práticas, envolvendo os conhecimentos estudados e pesquisados e as aprendizagens são registradas em vídeo e por escrito, em língua Guarani e em Língua Portuguesa.

No que se refere especificamente aos conhecimentos linguísticos, cabe destacar que nesta escola a alfabetização ocorre em língua Guarani. O português é aprendido posteriormente, como $2^{\text {a }}$ língua, privilegiando-se o trabalho com o texto escrito, mas em articulação com as demais práticas de uso da língua, principalmente com a oralidade, pois a aprendizagem dos saberes tradicionais se dá de forma direta e oral.

A organização curricular dessa escola sugere que os alunos do Curso de Formação de Professores Guarani do Sul e Sudeste do país - Kuo'a - Mbo'e - Conhecer - Ensinar - se envolveram com a proposta de elaborar o projeto político pedagógico específico para a escola Guarani como parte do seu processo de formação, na medida em que organizaram o ensino e a aprendizagem dos conhecimentos da cultura Guarani e da cultura ocidental em eixos temáticos relacionados aos saberes tradicionais do próprio povo, como proposto na "disciplina" Metodologia e desenvolvimento de pesquisa multicultural, e não por disciplinas como no PPC do próprio curso de formação, ainda que se tenha destacado as diferenças entre este curso e o Curso de formação e habilitação de professores de $1^{\mathrm{a}}$ a $4^{\mathrm{a}}$ séries do Ensino Fundamental para o contexto indígena Xokleng e Kaingang.

\section{ALGUMAS CONSIDERAÇÕES DENTRE AS MUITAS POSSÍVEIS}

Ao se revisitar a constituição histórica da educação escolar indígena no Brasil, particularmente no que se refere aos processos de formação de professores que se desenvolveram em diferentes momentos, tendo em vista a constituição de políticas de ensino bilíngue, observa- se que eles se evidenciam em duas das quatro fases indicadas na literatura da área. No entanto, a orientação que fundamenta tais projetos distingue-se fundamentalmente nesses dois momentos.

Na segunda fase - a da integração - o ensino bilíngue se colocou como um problema para o projeto de escolarização das populações indígenas, uma vez que se objetivava a integração dos índios à sociedade nacional. Nesse sentido, foram desenvolvidas ações de formação que previam a formação de indígenas como monitores bilíngues e a capacitação de professores não índios que já atuavam nas escolas indígenas, assim como o entrosamento de ambos, já que a proposta previa um trabalho conjunto.

Nesse período, o trabalho desenvolvido por professores e monitores junto às crianças nas escolas indígenas sustentava-se em um modelo de ensino bilíngue cujo objetivo consistia na retirada da língua materna do repertório do falante. Em outras palavras, os alunos iniciavam sua escolarização monolíngues em sua língua materna e, aos poucos, tornavam-se monolíngues na língua portuguesa. Pode-se dizer, assim, que nesse projeto de ensino bilíngüe as línguas indígenas foram o instrumento de sua própria extinção. Em uma ação de inculcação ideológica (BOUDIEU, 1974), os índios substituíam, aos poucos, as suas concepções tradicionais.

Na quarta fase - a das experiências de autoria - o ensino bilíngue resulta de uma ação das próprias populações indígenas, quando começam a pensar projetos de formação de professores alternativos aos propostos no contexto da política de integração nacional. Pode-se concluir que a dimensão positiva do bilinguismo passa a fundamentar as propostas de escolarização para as populações indígenas nesse período e, como tal, procura-se garantir a manutenção e o desenvolvimento das línguas indígenas nas escolas.

No ensino bilíngue que privilegia o enriquecimento linguístico, os alunos aprendem o português para que este possa ser acrescido ao seu repertório comunicativo, ao mesmo tempo em que aprimoram as suas competências de uso da língua materna. Nesse modelo de ensino, os alunos desenvolvem a capacidade de fazer uso de mais de uma língua para que delas possam lançar mão nas mais diferentes situações de interação em que estiverem envolvidos.

Considerando que essa concepção fundamenta, em alguma medida, os processos de formação de professores indígenas que se desenvolvem atualmente, inclusive os que foram analisados no contexto deste trabalho, 
faz-se necessário o desenvolvimento de estudos que demonstrem as competências que vem sendo desenvolvidas pelos alunos na aprendizagem das línguas envolvidas em seus processos de escolarização.

Se, em um momento da história da educação escolar indígena, as línguas indígenas foram utilizadas como meio de alcançar culturalmente essas populações, para integrá-las ao sistema de ensino nacional, atualmente assumem um papel de empoderamento desses grupos. A formação de professores pode se constituir, assim, em uma ação que valorize a diversidade linguística. Os cursos de formação realizados em Santa Catarina, em especial o do Curso de Formação de Professores Guarani do Sul e Sudeste do país - Kuo’a - Mbo’e Conhecer - Ensinar -, quando do cotejamento com o projeto político pedagógico de uma das escolas Guarani, podem ser ilustrativos das possibilidades de um projeto de formação de professores fundamentado em uma concepção de ensino bilíngue que amplie o repertório linguístico dos alunos. Sabe-se, porém, que os desafios a serem enfrentados ainda são muitos.

\section{REFERÊNCIAS}

BOURDIEU, Pierre. O mercado de bens simbólicos. In: A economia das trocas simbólicas. São Paulo: Perspectiva, 1974. p. 99-181.

BRASIL. Secretaria de Educação Fundamental. Referencial Curricular Nacional para as Escolas Indígenas RCENEI. Brasília: MEC/SEF, 1998.

DUTRA, Mara Vanessa et al. Krenak, Maxakali, Pataxó e Xakribá: a formação de professores indígenas em Minas Gerais. Revista Em Aberto, Brasília, v. 20, n. 76, fev. 2003, p. 74-88.

FERREIRA, Mariana Kawall Leal. A educação escolar indígena: um diagnóstico crítico da situação no Brasil. In: FERRREIRA, Mariana Kawall Leal; SILVA, Aracy Lopes da (Orgs.). Práticas pedagógicas na escola indígena. São Paulo: Global, 2001, p. 71-111.

HENTZ, Maria Izabel de Bortoli. Nas vozes da educação escolar indígena, os sentidos do discurso dos professores Xokleng como elemento constitutivo da identidade. 2005. Tese (Doutorado em Linguística) - Universidade Federal de Santa Catarina, Florianópolis.

MAHER, T., M. Do casulo ao movimento: a suspensão das certezas na educação bilíngüe e intercultural. In: CAVALCANTI, M.; BORTONI-RICARDO, S. M. (Orgs.). Transculturalidade, linguagem e educação. Campinas, SP: Mercado de Letras, 2007. p. 67-94.

MONTE, Nietta Lindenberg. Registros de práticas de formação. Revista Em aberto, Brasília, v. 20, n. 76: Experiências e desafios na formação de professores indígenas no Brasil, p. 1-239, fev. 2003 a. $2003 \mathrm{~b}$

Novos frutos das escolas da floresta: registros de práticas de formação. Rio de Janeiro: N. L. Monte,

Escolas da Floresta: entre o passado oral e o presente letrado - diários de classe de professores Kaxinawá. Rio de Janeiro: Multiletra, 1996.

NÓVOA, António. Os professores e sua formação. Lisboa: Dom Quixote, 1995.

Para uma análise das instituições escolares. In: NÓVOA, António. As organizações escolares em análise. Lisboa: Dom Quixote, 1992, p. 14-43.

OLIVEIRA, Gilvan Müller de (Org.). Declaração universal dos direitos lingüísticos: novas perspectivas em linguagem. Campinas, SP: Mercado das Letras, Associação de Leitura do Brasil (ALB); Florianópolis: IPOL, 2003.

PEGGION, Edmundo Antônio. Educação e diferença: a formação de professores indígenas em Mato Grosso. Em aberto, v. 20, n. 76: Experiências e desafios na formação de professores indígenas no Brasil, fev. 2003, p. 44-53.

SANTA CATARINA, Secretaria de Estado da Educação e do Desporto. Proposta Curricular de Santa Catarina: educação infantil, ensino fundamental e médio: temas multidisciplinares. Florianópolis: COGEN, 1998.

SANTOS, Sílvio Coelho dos. Educação e sociedades tribais. Porto Alegre: Movimento, 1975. 
Os índios Xokleng e os imigrantes. In: FLEURI, Reinaldo Matias (Org.). Intercultura e movimentos sociais. Florianópolis: MOVER/NUP, 1998. p. 57-69.

SILVA, Maria Socorro Pimentel da. A função social do mito na revitalização cultural da língua Karajá. 2001. Tese (Doutorado em Lingüística Aplicada e Estudos da Linguagem) - Pontifícia Universidade Católica, São Paulo.

TASSINARI, Antonella Maria Imperatriz. Da civilização à tradição: os projetos de escola entre os índios do Uaçá. In: FERRREIRA, Mariana Kawall Leal e SILVA, Aracy Lopes da (Org.). Antropologia, história e educação. São Paulo: Global, 2001.

TRONCARELLI, Maria Cristina e outros. A formação de educadores indígenas para as escolas xinguanas. Em aberto, Brasília, v. 20, n. 76: Experiências e desafios na formação de professores indígenas no Brasil, fev. 2003, p. 54-73.

Recebido em 11/11/13. Aprovado em 19/12/13. 